\title{
FUNDAMENTACIÓN DE LA SENTENCIA Y CONTRADICCIÓN, COMO MATERIALIZACIÓN DEL DERECHO AL RECURSO EN MATERIA PROCESAL PENAL*
}

\author{
Diego Palomo Vélez** \\ Humberto Alarcón CORSi***
}

\section{Sentencia excelentísima Corte Suprema de 9 de noviembre de 2009, Rol N ${ }^{\circ} 2511-2009$}

Vistos:

En la causa RUC No 0600448639-9, RIT № 421-2008 seguida ante el Tribunal de Juicio Oral de Concepción, por sentencia de seis de diciembre de dos mil ocho se absolvió a Víctor Adolfo Muñoz Muñoz del cargo de ser autor del delito reiterado de abuso sexual supuestamente ocurrido en la ciudad de Concepción en el primer semestre de dos mil seis. Enseguida, condenó al mencionado Muñoz Muñoz como autor del delito de violación impropia en perjuicio de la menor de iniciales Y.S.M.R., en grado de consumado, previsto y sancionado por el artículo 362 del Código Penal, acaecido durante el primer semestre del año dos mil seis en la comuna de Concepción, a cinco años y un día de presidio mayor en su grado mínimo, accesorias de inhabilitación absoluta perpetua para cargos y oficios públicos y derechos políticos e inhabilitación absoluta para profesiones titulares mientras dure la condena, más el pago de las costas del litigio. Se impuso, además, la privación de la patria potestad sobre la menor, si la tuviere, quedando inhabilitado para obtenerla, si no la tuviere, y de todos los derechos que por el ministerio de la ley se le confieren respecto de la persona o bienes de la ofendida, de sus ascendientes o descendientes,

* Los autores agradecen al abogado José Araneda Henríquez, por la remisión de uno de los fallos que acá se comentan, lo que motivó la realización de este trabajo. Colaboración recibida el 1 de abril y aprobada el 22 de abril de 2011.

** Profesor de Derecho procesal en la Facultad de Ciencias Jurídicas y Sociales de la Universidad de Talca; Doctor en Derecho por la Universidad Complutense de Madrid, España. Correo electrónico: dpalomo@utalca.cl.

*** Profesor de Derecho penal en la Facultad de Ciencias Jurídicas y Sociales de la Universidad de Talca; Master en Derecho penal y ciencias penales Universidad de Barcelona y Pompeu Fabra, España. Es Defensor Local Jefe, Defensoría Local de Concepción. Correos electrónicos: halarcon@utalca.cl. 
conservando, por el contrario, todas las obligaciones legales cuyo cumplimiento vaya en beneficio de la víctima o de sus descendientes. Se sancionó también al enjuiciado con la pena de interdicción del derecho de ejercer la guarda de la menor ofendida y ser oído como pariente en los casos que la ley designa y la sujeción a la vigilancia de la autoridad durante los diez años siguientes al cumplimiento del castigo temporal principal, en la forma señalada en la parte final del inciso primero del artículo 372 del Código Penal.

La defensa del imputado, representada por el abogado Álvaro Araya Fuentes, interpuso un recurso de nulidad sustentado en la causal contenida en el artículo 373, letra a), del Código Procesal Penal, motivada en la infracción al debido proceso, al derecho a ser oído y a la igualdad de armas; en subsidio, asilado en la misma causal del artículo 373, letra a), esta vez fundado en el derecho a contar con un tribunal imparcial, y por último, también de modo subsidiario, en virtud del artículo 374, letra e), en relación al 342, letra c), ambos del mismo ordenamiento procesal, debido a la falta de fundamentación de la decisión.

Esta Corte, por resolución de cuatro de marzo de dos mil nueve, procediendo de conformidad a lo dispuesto en el artículo 383, inciso tercero, letra a), del estatuto procesal del ramo, dispuso pasar los antecedentes a la Corte de Apelaciones de Concepción a fin de que, si lo estimase admisible, conozca y falle el recurso de nulidad instaurado.

El tribunal de alzada, por decisión de nueve de abril del año en curso, resolvió rechazar el arbitrio y declarar que el fallo del Tribunal Oral no es nulo, como tampoco el juicio oral en que se pronunció.

En contra de esta sentencia recurrió de queja el abogado Álvaro Araya Fuentes, defensor penal público, como se desprende de fojas 56 a 60 vuelta, recurso que fue declarado inadmisible por resolución de dieciocho de mayo último. Sin perjuicio, en uso de las facultades disciplinarias de esta Corte, se dispuso recabar informe a los Ministros recurridos.

A fojas 70, los señores Ministros y Fiscal Judicial evacuan el informe requerido, señalando que ninguna de las causales de nulidad alegadas por la defensa resultaron acreditadas; en particular, en lo que aquí interesa, sostienen que la contenida en la letra a) del artículo 373, fundada en la imparcialidad del juzgador, no fue alegada por el recurrente en la audiencia y, someramente, en relación a las restantes, aluden a las motivaciones de su rechazo haciendo exclusiva referencia a las explicaciones de los sentenciadores del fondo que, según su parecer, no permitían prestarles acogida.

A fojas 74 , se ordenó traer los autos en relación.

CON LO RELACIONADOY CONSIDERANDO:

PRIMERO: Que el compareciente explica que el arbitrio de nulidad instaurado contra la sentencia condenatoria pronunciada por el Tribunal Oral de Concepción se sustentó en el artículo 373, letra a), del Código Procesal Penal, de- 
nunciando la infracción al debido proceso, al derecho a ser oído y a la igualdad de armas; en subsidio, en el artículo 373, letra a) de la misma recopilación legal, reclamando la transgresión del derecho a un tribunal imparcial; y finalmente, también en subsidio, en el artículo 374, letra e), en conexión al artículo 342, letra c), del mencionado compendio normativo, por falta de fundamentación del fallo. Añade que por decisión de cuatro de marzo pasado, este tribunal ordenó la remisión de los antecedentes a la Corte de Apelaciones de Concepción porque, en lo pertinente, estimó que "los hechos en que la defensa hace consistir la causal de la letra a) del artículo 373 del Código Procesal Penal, de competencia de esta Corte Suprema, dicen relación con el impedimento del ejercicio de facultades de la defensa, por un lado, y con la imparcialidad del tribunal, por el otro, cuestiones que se encuadran específicamente en los motivos absolutos de nulidad previstos en las letras c) y a) del artículo 374 del mismo cuerpo legal, respectivamente". Refiere el quejoso que el treinta y uno de marzo se realizó la audiencia en el tribunal de alzada, dándose a conocer su decisión el nueve de abril último. Sin embargo, el indicado veredicto omitió pronunciarse acerca de la causal de la letra a) del artículo 373, del Código Procesal Penal, fundada en el derecho a un tribunal imparcial, misma que esta Corte estimó comprendida en el artículo 374, letra a), del mismo texto legal. De ese modo, reprueba la ausencia de resolución de todas las causales sometidas a consideración del tribunal ad quem, haciendo caso omiso a lo prescrito en los artículos 36 y 384 , del Estatuto Adjetivo Criminal; $6^{\circ}, 7^{\circ}$, y 73 , de la Constitución Política de la República; y $10^{\circ}$ del Código Orgánico de Tribunales, faltando a su deber de decidir acerca de todas las cuestiones entregadas a su conocimiento.

SEGUNDO: Que de la lectura del libelo de nulidad promovido por la defensa, bajo el capítulo II.-, reclama como garantía conculcada el derecho a un tribunal imparcial, toda vez que para resolver la materia que fue llamado a decidir tuvo especial consideración con la información incorporada al juicio por el propio tribunal y no por los intervinientes, defecto que estima se produce con ocasión de la declaración del perito médico legista Darío Benavente Aldea y las preguntas que los magistrados le formulan de acuerdo con el artículo 329 del Código Procesal Penal, intervención transgresora que se materializó finalmente en la decisión.

TERCERO: Que la resolución de la Corte de Apelaciones de Concepción, si bien en su sección expositiva indica que el recurso de nulidad de la defensa invoca las causales de los artículos 373, letra a) y 374, letra e), del Código Procesal Penal, y que la primera, encuadra en los motivos absolutos de nulidad del artículo 374, letras a) y c), no extiende ninguno de sus razonamientos a la imparcialidad del juzgador, cuyo quebranto originó específicamente uno de los motivos subsidiarios de anulación, falencia que justifican los recurridos en su informe al decir que tal capítulo de impugnación no fue reclamado en estrados. 
CUARTO: Que según ordena el artículo 384 del Código Procesal Penal, la Corte, al fallar un recurso de nulidad, deberá exponer los fundamentos que sirvieren de base a su decisión y pronunciarse sobre las cuestiones controvertidas, salvo que acogiere el recurso, en cuyo caso podrá limitarse a la causal o causales que le hubieren sido suficientes.

QUINTO: Que la acertada inteligencia de la primera parte de la citada norma permite concluir que por imperativo legal toda sentencia que resuelva un recurso de nulidad debe contener la enunciación y desarrollo de los razonamientos por los cuales se emite el pronunciamiento en relación a cada uno de los asuntos sometidos a la decisión del tribunal, lo que supone la concreción de un deber fundamental del órgano jurisdiccional que no es más que una reiteración de la obligación de los tribunales de la carga inexcusable de resolver, en todo caso, los asuntos que conozcan -artículo 10 del Código Orgánico de Tribunales.

La omisión de pronunciamiento sobre una de las pretensiones deducidas vulnera necesariamente lo dispuesto en la legislación, que fija con toda precisión las condiciones y el contenido de su actividad, de manera que, si esos presupuestos no se satisfacen, deviene en una manifiesta infracción a su deber público fundamental.

SEXTO: Que, en este orden de ideas, basta una simple comparación entre el planteamiento formulado en el recurso de nulidad deducido, en lo relacionado con la falta de imparcialidad del tribunal oral que conoció del asunto, y lo expresado en la resolución que denegó el mentado arbitrio, donde ninguna mención hace sobre esta alegación esgrimida en tiempo y forma por el quejoso, de manera tal que el impugnante no está en condiciones de conocer la suerte de este extremo del recurso.

SÉPTIMO: Que la afirmación de los recurridos sobre este tópico, avalando su proceder en la falta de alegación del recurrente en torno al indicado acápite de la nulidad, no es efectiva, pues no se ajusta al mérito de lo debatido en la vista de la causa. Basta la verificación del contenido del registro de audio del treinta y uno de marzo pasado, minuto 9,43 y siguientes, para constatar que la imparcialidad del tribunal fue expresamente discutida, de manera que el dictamen en referencia no contiene todos y cada uno de los presupuestos que ordena la ley en forma precisa y determinada, es decir, que contenga las razones en las cuales se sustenta la decisión, advirtiéndose la falta de fundamentos de una de las causales que comprendía el recurso de nulidad.

OCTAVO: Que, en todo caso, el alcance que los recurridos pretenden otorgar a la supuesta falta de alegación sobre un capítulo del recurso de nulidad no tiene sustento legal.

NOVENO: Que, en definitiva, con lo relacionado, queda establecido que los jueces de la Segunda Sala de la Corte de Apelaciones de Concepción, al 
dictar la sentencia de nueve de abril de dos mil nueve, escrita de fojas 2 a 5 de este cuaderno, incurrieron en falta grave que habilita a este tribunal a hacer uso de las facultades disciplinarias y proceder de oficio, que le autoriza el artículo 545 del Código Orgánico de Tribunales.

Por estas consideraciones y de acuerdo, además, con lo dispuesto en los artículos 545 y 549 del Código Orgánico de Tribunales, PROCEDIENDO DE OFICIO, SE DEJA SIN EFECTO la resolución de nueve de abril de dos mil nueve que falló el recurso de nulidad instaurado en la causa RIT 421-2008, RUC 0600448639-9, del Tribunal Oral en lo Penal de Concepción, ingresado a la Corte de Apelaciones de esa ciudad bajo el N 112-2008 RPP, cuya transcripción rola de fojas 2 a 5 de estos autos (fojas 71 a 73 del cuaderno traído a la vista), reponiéndose el procedimiento al estado que el tribunal no inhabilitado que corresponda se pronuncie, conozca y falle el recurso de nulidad entablado por la defensa del condenado en el referido proceso.

No se dispone la remisión de los antecedentes al Pleno de este tribunal, por estimar que no existe mérito suficiente para ello.

Se previene que el Ministro señor Rodríguez fue de parecer de enviar tales piezas al tribunal Pleno, como lo ordena el artículo 545 del Código Orgánico de Tribunales, por ser esta materia de su exclusiva competencia.

Comuníquese por la vía más expedita esta resolución a la Corte de Apelaciones de Concepción y al Tribunal del Juicio Oral en lo Penal de Concepción.

Sin perjuicio, agréguese copia autorizada de la misma a las actuaciones extraídas del Sistema Computacional No 112 - 2009 RPP, Rol de la Corte de Apelaciones de Concepción, tenidos a la vista y devuélvaselos en su oportunidad.

Regístrese y archívese.

Redacción del Ministro Sr. Rubén Ballesteros.

Rol N²511-09.

\section{Sentencia excelentísima Corte Suprema de fecha 26 de abril de 2010, ROL N 9492-09}

Santiago, veintiséis de abril de dos mil diez.

En los autos Rol de la Corte de Apelaciones de Talca No 545-2009 R.P.P., sobre recurso de nulidad, vinculado a su vez al RUC 0800663058-9, RIT 27-2009 del Tribunal de Juicio Oral de Talca, caratulado Ministerio Público contra Iván Bautista Tobar Tapia y otros, seguidos por los delitos reiterados de receptación y robo con fuerza en lugar habitado, en los que figuran como imputados Iván Bautista Tobar Tapia, Marcia del Carmen Maturana Casanga, Esteban Antonio Aranguez Alvarez e Iván Bautista Tobar Maturana, recurre de queja el abogado Roberto Montecinos Flores en representación de los sentenciados ya singulari- 
zados, respecto de los Ministros de la Segunda Sala de la Corte de Apelaciones deTalca, señores Rodrigo Biel Melgarejo y Vicente Fodich Castillo, así como del Abogado Integrante Sr. Rodrigo Barcia Lehmann, en razón de las faltas o abusos en que éstos habrían incurrido al rechazar sin las debidas motivaciones su recurso de nulidad intentado respecto de la sentencia condenatoria ya referida.

A fojas 9 y siguiente, figura la resolución de esta Corte Suprema en la que se declaró inadmisible el presente recurso de queja interpuesto, pero en uso de las facultades disciplinarias oficiosas igualmente se ordenó recabar informe a los recurridos.

A fojas 25, rola el informe de los jueces recurridos quienes expresan que no han incurrido en las faltas o abusos que se les atribuyen, toda vez que en la decisión adoptada de rechazar el recurso de nulidad interpuesto por el recurrente de queja, se hicieron debido cargo de cada uno de los aspectos que ahora da por infringidos el recurrente, los que se citaron en la parte considerativa de la respectiva sentencia.

Luego, agregan que el veredicto del Tribunal Oral en lo Penal de Talca estableció con precisión los hechos por los cuales se condenó a los imputados, valorando para ello la prueba rendida en el juicio, sin observar errónea aplicación del derecho, toda vez que se configuran los ilícitos establecidos en la misma, sin que exista omisión de los requisitos que debe contener todo fallo, explicando la forma en que arribaron a la convicción de autoría y consiguientemente la inexistencia de faltas a la lógica, máximas de las experiencia o a los conocimientos científicamente afianzados, toda vez que se trata de una sentencia que se explica por sí misma y cumple con las exigencias legales.

Finalmente, informan que tampoco observaron infracción al principio de congruencia, toda vez que los hechos y delitos por los cuales fueron sancionados los imputados se encuentran incluidos en la acusación formulada por el Ministerio Público, por ello es que al tratarse de un recurso de nulidad de derecho estricto sin que el tribunal pueda variar los hechos establecidos por el tribunal oral en lo penal, se procedió al rechazo del libelo de nulidad, estimando que no cometieron ninguna falta o abuso grave en ello.

A fojas 31, se trajeron los autos en relación.

\section{CON LO RELACIONADO Y CONSIDERANDO:}

PRIMERO: Que, el compareciente reprocha a los sentenciadores ya precisados una serie de errores manifiestos y graves cometidos al resolver su recurso de nulidad interpuesto respecto de la sentencia condenatoria que afectó a sus defendidos emitida por el tribunal de juicio oral en lo penal de la ciudad de Talca, ello al resolver las tres causales allí interpuestas, que fueron la del artículo 373 letra b), por la errónea aplicación del derecho; la del artículo 374 letra e), por la omisión de los requisitos establecidos en el artículo 342 letra c); y, por 
último, la del artículo 373 letra f) en relación al artículo 341, referida al principio de congruencia, normas todas del Código Procesal Penal, las que fueron deducidas en forma conjunta.

SEGUNDO: Que, sin embargo, como ya se precisó en la parte expositiva de esta sentencia, el recurso de queja interpuesto a fojas 5 fue declarado inadmisible, conforme reza de la resolución de fojas 9 y sin perjuicio de ello, y en uso de las facultades disciplinarias oficiosas, se ordenó igualmente recabar informe de los jueces recurridos, los que debían remitir todos los antecedentes que incidieran en la resolución impugnada, lo que fue cumplido a fojas 25.

TERCERO: Que, del examen de la carpeta remitida correspondiente al RUC 0800663058-9, RIT 27-20009, del Tribunal de juicio Oral en lo Penal de Talca, consta que con fecha veintiocho de octubre de dos mil nueve se dictó sentencia definitiva en la que resultaron condenados las siguientes personas, a las penas que en cada caso se precisan: 1.- Iván Bautista Tobar Tapia, la de cuatro años de presidio menor en su grado máximo, accesorias legales y al pago de una multa de cinco unidades tributarias mensuales así como respecto de las costas del procedimiento, todo por ser autor de un delito consumado de receptación de especies ocurrido el 29 de julio de 2008; 2.- Marcia del Carmen Maturana Casanga, la de tres años de presidio menor en su grado medio, accesorias legales y al pago de una multa de cinco unidades tributarias mensuales como al de las costas del procedimiento, por ser autora del delito consumado de receptación de especies ocurrido el 29 de julio de 2008; 3.- Esteban Antonio Aranguez Álvarez, la de cinco años y un día de presidio mayor en su grado mínimo, accesorias legales, y al pago de las costas del juicio, como autor de un delito consumado de robo con fuerza en las cosas en lugar destinado a la habitación acaecido el 25 de julio de 2008; y 4.- Iván Bautista Tobar Maturana, la de tres años y un día de internación en régimen cerrado con programa de reinserción social por ser autor de un delito consumado de robo con fuerza en las cosas efectuado en lugar habitado, ocurrido el 25 de julio de 2008. En la misma resolución, sólo se concedió el beneficio alternativo de la remisión condicional de la pena a Marcia del Carmen Maturana Casanga.

CUARTO: Que, el abogado recurrente de queja, planteó respecto de la sentencia reseñada en el motivo anterior un recurso de nulidad con fecha 7 de noviembre de 2009, actuando en representación de los sentenciados Iván Tobar Maturana, Iván Tobar Tapia y Marcia Maturana Casanga, expresando como motivaciones del mismo un total de tres causales, deducidas en forma conjunta. La primera de ellas, en la letra b) del artículo 373 del Código Procesal Penal, esto es, errónea aplicación del derecho con influencia sustancial en lo dispositivo del fallo. En un segundo aspecto, en la letra e) del artículo 374 del Código Procesal penal, por la omisión en la sentencia de los requisitos exigidos en el artículo 342 letra c) del mismo Código; y, finalmente, en la causal del artículo 
374 letra f) del Código Procesal Penal, en relación al 341 del mismo Código, infracción al principio de congruencia.

QUINTO: Que, en lo que toca al desarrollo de la primera causal de nulidad, ésta se subdividió en dos aspectos; por un lado para reclamar respecto de la determinación de la agravante de responsabilidad contenida en el artículo 456 bis $\mathrm{N}^{\circ} 3$ del Código Penal, esto es, la pluralidad de malhechores en el delito de robo con fuerza en lugar destinado a la habitación, cuestionando que para su consumación, dado los términos expresados por el fallo, no se necesitaba de la participación de dos personas, sino que perfectamente se podía haber cometido por una sola, sin haber mayor peligro para las víctimas, que no estaban presentes en su casa, y que tampoco se requirió de la cooperación para que tuviera éxito el cometido. Agregando que la caja la portaba uno solo de los hechores, según el testigo Juan Carlos Díaz. El otro extremo atacado por esta primera motivación de nulidad, fue la infracción del artículo 456 bis A del Código Penal, al condenar a Iván Tobar Tapia y Marcia Maturana Casagna como co-autores del delito de receptación, por las razones que allí mismo se explicitan.

SEXTO: Que, contrastando la anterior circunstancia con el texto de la sentencia dictada por la Corte de Apelaciones de Talca, que conociendo del anterior libelo y el de adhesión de la defensa de Aránguez Albornoz, en lo que respecta a la primera causal en su primer aspecto, sólo se hace referencia de ello en la parte expositiva de la misma, conforme se aprecia de su párrafo cuarto a modo de resumen de lo cuestionado por el impugnante.

Sin embargo, en su parte considerativa no se contiene ningún fundamento, razón o motivo que permita conocer el juicio que tuvieron los sentenciadores en relación a dicho capítulo del reclamo del recurrente, limitándose en cambio por los motivos primero a sexto, a fortalecer la sentencia atacada en cuanto a sostener que ella contiene una exposición clara de los hechos, y la acreditación de los tipos penales del robo con fuerza y de la receptación.

SÉPTIMO: Que, en el motivo tercero se afirma que no se incurrió en una errónea aplicación del derecho con influencia sustancial en los dispositivo del fallo, en ninguno de los dos ilícitos investigados. En el cuarto, aprecia que en la sentencia se efectúa una exposición clara, lógica y completa de cada uno de los hechos y circunstancias que se dieron por probados; sin que la valoración efectuada haya vulnerado el artículo 297 del Código Procesal Penal.

Más adelante, en el motivo quinto se hace referencia a que no se excede el contenido de la acusación ni se afecta el principio de congruencia, por cuanto los hechos constitutivos de la sentencia están contenidos en la acusación fiscal.

Finalmente, en el motivo sexto, se afirma que la nulidad no es una segunda instancia, conforme a lo cual se pueda pretender una recalificación de los hechos que producen consecuencias jurídicas en el juicio, rechazando el recurso 
de nulidad interpuesto por el abogado Roberto Montecinos Flores y la adhesión del profesional David Bahamondes Barde.

OCTAVO: Que, de lo anterior, aparece de toda evidencia que no existe decisión en ningún sentido respecto de la materia propuesta por el recurrente de nulidad en su respectivo libelo de igual carácter, en lo que toca al numeral 1) de la primera causal alegada, esto es, a la inconcurrencia de la circunstancia agravante de responsabilidad de la pluralidad de malhechores, la que figura aplicada en el motivo décimo del fallo del Tribunal Oral en lo Penal de Talca, respecto de los acusados Aranguez Albornoz y Tobar Maturana, en el delito de robo con fuerza en lugar destinado a la habitación. Sin que pueda estimarse de suficiente paliativo o razón, lo referido en el informe de los recurridos que rola a fojas 25 y siguientes, en donde expresaron que: lo primero que se indica es que la sentencia no se refirió a la agravante de pluralidad de malhechores, pero de la sentencia recurrida de nulidad, como de las alegaciones del Defensor Público y lo alegado en la vista del recurso se aprecia que lo que se alega es que no se habría probado el escalamiento, ni la participación, aseveración que ni siquiera se encuentra incluida en el fallo respectivo. De modo tal que lo cierto es que en el recurso existe un cuestionamiento expreso de una materia determinada, lo que se encuentra sin decisión en el fallo, desde que no recibió ningún tratamiento por parte del tribunal de alzada de Talca, a lo que se encontraba obligado dada la naturaleza de derecho estricto que tiene el recurso de nulidad.

NOVENO: Que, conforme se aprecia, el aspecto esencial detectado de oficio y cuestionado por el recurrente en su recurso de queja que fuera declarado inadmisible, es el concerniente a la ausencia de fundamentación en la decisión que adoptaron los Ministros recurridos, al resolver el catorce de diciembre de dos mil nueve rechazando el recurso de nulidad y la adhesión que generaron la vista de ese día.

DÉCIMO: Que, la exigencia de motivación en las decisiones adoptadas por los órganos jurisdiccionales en el nuevo sistema procesal penal, se encuentra consagrada en el artículo 36 del Código Procesal Penal, en donde se indica que: Será obligación del tribunal fundamentar las resoluciones que dictare, con excepción de aquellas que se pronunciaren sobre cuestiones de mero trámite. La fundamentación expresará sucintamente, pero con precisión, los motivos de hecho y de derecho en que se basaren las decisiones tomadas. La simple relación de los documentos del procedimiento o la mención de los medios de prueba o solicitudes de los intervinientes no sustituirá en caso alguno la fundamentación.

UNDÉCIMO: Que, la antedicha disposición ya figuraba en el anteproyecto como artículo 40, con la salvedad que se incluía en la parte final del inciso primero la frase siguiente: La fundamentación expresará con precisión los motivos de hecho y de derecho en que se basan las decisiones tomadas. Más adelante, 
en la Cámara de Diputados se ubicó como artículo 42, respecto de cuyo texto anterior, la Comisión le introdujo modificaciones formales, expresando ahora que: La fundamentación expresará sucintamente, pero con precisión, los motivos de hecho y de derecho en que se basaren las decisiones tomadas, señalando como explicación de aquello, lo que se mencionó en el primer informe de la Comisión de Constitución Legislación y Justicia, la que expresó lo siguiente: El artículo 42 se modificó para dejar sentado que ella deberá expresar, sucintamente, pero con precisión, los motivos de hecho y de derecho en que se sustenten, agregando que el proyecto intenta, mediante este principio, evitar la habitual práctica de fundamentar las resoluciones judiciales sólo en términos formales, lo que produce, por una parte, un alto grado de insatisfacción en la ciudadanía al no cumplir con el efecto socializador propio de las sentencias judiciales y, por otra, impide a las partes comprender la razón de lo decidido. Esto permite, a la vez, la creación de una jurisprudencia que determine de manera clara los parámetros de interpretación de las normas jurídicas.

El respeto de este principio hará que la eficacia de las resoluciones judiciales encuentre apoyo en una adecuada fundamentación de los motivos y consideraciones tenidas a las vistas para resolver en un determinado sentido.

Luego, en el Senado la Comisión respectiva aprobó la norma con modificaciones sólo de forma, reemplazando de su inciso primero las expresiones dicte, pronuncien y basen, por: dictaren, pronunciaren y basaren, respectivamente. En tanto que en el inciso segundo, se reemplazó la frase "no sustituirán en ningún caso" por no sustituirá en caso alguno, lo que se efectuó por unanimidad, con los votos de los HH. Senadores Señores Aburto, Diez, Larraín y Viera-Gallo, quedando su texto inalterable hasta la fecha.

DUODÉCIMO: Que, el anterior requerimiento de motivación de las resoluciones judiciales en el nuevo sistema procesal penal, constituye un requerimiento impuesto por el derecho al juicio previo, consagrado a nivel constitucional en el artículo 19 № 3, inciso quinto, de la Constitución Política de la República, y a nivel legal en el artículo $1^{\circ}$ del Código Procesal Penal, ello como necesidad de legitimidad de ese tipo de decisiones, lo que no se satisface con meras referencias formales al hecho de haberse cumplido los estándares legales o a la existencia de antecedentes generales invocados, y en cada caso se debe indicar con precisión los motivos de hecho y de derecho en que se fundan las decisiones tomadas.

DÉCIMO TERCERO: Que, el derecho al juicio previo y única persecución, y el derecho a sentencia judicial de condena como fundamento de la pena, son consecuencia de la prohibición de la autotutela en materia penal y del monopolio estatal en materia de persecución criminal y esa noción de juicio es sinónima de sentencia, íntimamente ligada a la idea de juicio lógico o razonamiento fundado en premisas, expresando la fundamentación de la sentencia, lo 
que constituye una garantía para el imputado y las partes derivadas del derecho al juicio previo, conforme al artículo $19 \mathrm{~N}^{\circ} 3$ inciso quinto de la Constitución Política de la República, y que a nivel legal se encuentra elevado a la categoría de principio básico en el artículo $1^{\circ}$ del Código Procesal Penal, en particular en la parte final del inciso primero, en donde dispone que: Toda persona tiene derecho a un juicio previo, oral y público, desarrollado en conformidad con las normas de este cuerpo legal.

DÉCIMO CUARTO: Que, por ello es que la sentencia no efectuó las consideraciones suficientes de hecho ni de derecho en forma concreta y determinada sobre la cuestión propuesta, aspectos que los jueces de la Corte de Apelaciones de Talca recurridos de queja no se preocuparon ni cuidaron de considerar al adoptar su rechazo final, eludiendo un aspecto complejo de la discusión, en que era del todo imprescindible y necesario que el fallo impugnado contuviera las consideraciones pertinentes, que la analizara y razonara en cada caso para adoptar cada una de sus decisiones, y evitar con ello, como ocurrió en la especie, que el veredicto adoptado carezca absolutamente de explicación a ese respecto, omisión que tiene un carácter objetivo, bastando con contrastar el veredicto con lo discutido en el recurso correspondiente, para detectar lo acontecido, sin que corresponda por lo expresado aquilatar el mérito intrínseco de ello o el valor de convicción que deba atribuírseles, lo que se encuentra expresamente impedido por el inciso segundo del artículo 36 del Código Procesal Penal.

DÉCIMO QUINTO: Que, la debida fundamentación de toda resolución judicial es una garantía constitucional y forma parte del control jurisdiccional y público que caracteriza el nuevo proceso penal. Además de ser un deber constitucional del juzgador, es un derecho del justiciable al reexamen de la cuestión sometida a decisión ante jueces distintos. El deber de motivar las sentencias es un componente esencial del modelo de jurisdicción propio de un estado democrático de derecho. Si se comparten los fundamentos de la resolución impugnada, es exigible, al menos, una motivación del porqué se está de acuerdo con la decisión de primer grado, es decir, publicar las razones de la decisión. El uso del mero reenvío como técnica motivacional de la sentencia no cumple con el deber de explicitar el valor que le merece al sentenciador de segunda instancia las argumentaciones a que se remite. Un reenvío formal y general vulnera el derecho del justiciable a obtener una sentencia motivada y pone en entredicho el valor efectivo que pueda tener la doble instancia en nuestro derecho.

Que, por estas consideraciones y lo prevenido en los artículos 540, 545 y 549 del Código Orgánico de Tribunales, y los artículos 1², 36, 248, 249, 250, 251, 253 y 256 del Código Procesal Penal, el 19 № 3 inciso quinto de la Constitución Política de la República, en uso de las facultades disciplinarias oficiosas con que cuenta este máximo tribunal, y poniendo pronto remedio al mal que 
lo motiva, SE DEJA SIN EFECTO la resolución dictada por la Segunda Sala de la Corte de Apelaciones de Talca, que es de fecha catorce de diciembre de dos mil nueve, que rola a fojas 19 a 23 del cuaderno traído a la vista, y se repone la causa al estado que la referida Corte de Alzada integrada por ministros no inhabilitados proceda a celebrar una nueva audiencia en la cual se discutan y resuelvan, conforme a derecho, las materias propuestas por el recurso de nulidad del abogado Sr. Roberto Montecinos Flores, como de quien adhirió al anterior, correspondiente al profesional Sr. David Bahamondes Barde.

No se dispone la remisión de estos antecedentes al Tribunal Pleno.

Se previene que el Ministro señor Rodríguez fue de parecer de enviar tales piezas al Tribunal Pleno, como lo ordena el artículo 545 del Código Orgánico de Tribunales, por ser esta materia de su exclusiva competencia.

Regístrese, agréguese copia autorizada de esta resolución al cuaderno tenido a la vista, y devuélvanse en su oportunidad.

Redacción del Abogado Integrante Sr. Luis Bates Hidalgo.

Rol N 9492-09.

\section{Sentencia de la excelentísima Corte Suprema de FECHA 28 DE FEBRERO DE 2011, ROL N 493-2011}

Santiago, veintiocho de febrero de dos mil once.

Vistos:

En la causa RUC N0901036186-6, RIT N7572-2010 seguida ante el Tribunal de Garantía de Temuco, por sentencia de veintiuno de septiembre de dos mil diez, se condenó a Waldemar Andrés Cepeda Valenzuela a la pena de trescientos días de presidio menor en su grado mínimo, suspensión de cargo y oficio público durante el tiempo de la pena, como autor del delito de maltrato habitual en violencia intrafamiliar, descrito y sancionado en el artículo 14 de la Ley $N^{\circ} 20.066$, por los hechos ocurridos desde fines del año dos mil cinco hasta el año dos mil nueve.

El defensor del imputado Cepeda Valenzuela interpuso recurso de nulidad contra la decisión de primer grado, que fue sustentado en la causal del artículo 373, letra a), del Código Procesal Penal; en subsidio, asilado en el artículo 374, letra f), en relación al artículo 341 del mencionado texto legal; y por último, también de modo subsidiario, invocó el artículo 373, letra b), del Código del ramo.

Esta Corte, por resolución de veintidós de noviembre de dos mil diez, procediendo de conformidad a lo dispuesto en el artículo 383, inciso tercero, letra a), del Código Procesal Penal, estimó que la causal del artículo 373 letra a), esgrimida por el imputado y que le otorga competencia a este tribunal, encuadraba específicamente en el motivo absoluto de nulidad previsto en el artículo 374, 
letra e), del indicado estatuto procedimental, por lo que, acorde a ello, remitió los antecedentes a la Corte de Apelaciones de Temuco para el conocimiento y fallo del recurso instaurado.

El tribunal de alzada, por decisión de siete de enero del presente año, resolvió rechazar el recurso y declarar que el fallo del Tribunal de Garantía no es nulo.

En contra de esta sentencia recurrió de queja el abogado señor José Ignacio Araneda Henríquez, defensor penal del imputado Waldemar Cepeda Valenzuela, como se desprende de fojas 19 a 29 vuelta, arbitrio que fue declarado inadmisible por resolución de veintiuno de enero último, a fojas 32. Sin perjuicio, en uso de las facultades disciplinarias de esta Corte, se dispuso recabar informe a los jueces recurridos.

A fojas 36, los señores Ministros y la señora Fiscal Judicial que dictaron el fallo, evacuan el informe requerido señalando que la decisión que adoptaron contiene en su fundamento quinto el desarrollo de los dos extremos reclamados por la primera causal, al expresar que, la defensa, no justifica como se produjo la infracción al artículo $19 \mathrm{~N}^{\circ} 3$ inciso $5^{\circ}$ de la Constitución Política y respecto al siguiente acápite, en el segundo argumento de la misma causal, se indica, en (sic) que se trata de impugnar los fundamentos de la sentencia, pero ello no sirve para dar motivo a un recurso de nulidad, tal como lo advierte, la Excma. Corte y que correspondería a la causal del artículo 374 letra e) del Código de Enjuiciamiento. Añaden que el grueso del alegato fue sobre la suposición de intenciones de la juez a quo, que habría alterado conscientemente el año de ocurrencia del primer hecho, para salvar un yerro en la aplicación del derecho, pero estiman que no se indicó de modo alguno, el porqué de esa actuación, cercana a la prevaricación, y qué motivos podrían imputársele a la Juez para actuar de esa manera: Enseguida explican que la reflexión sexta de su decisión se refiere al segundo motivo de nulidad y por qué no se estima configurado, pues aducen que el tribunal razonó extensamente sobre la prueba rendida entendiéndose como un simple error la fecha del primero de los episodios de violencia, por lo que hubo congruencia entre el requerimiento y la sentencia condenatoria, para concluir afirmando que dada la extensión del fallo y la valoración de la prueba y alegatos antes expresados, se estimó que resultaba inoficioso analizar la última causal alegada.

A fojas 39, se ordenó traer los autos en relación.

\section{CON LO RELACIONADOY CONSIDERANDO:}

PRIMERO: Que el defensor penal, señor José Ignacio Araneda Henríquez, en representación del enjuiciado Waldemar Andrés Cepeda Valenzuela, explica en su presentación de fojas 19 y siguientes, que el arbitrio de nulidad intentado contra la sentencia condenatoria pronunciada por el Juzgado de Garantía de Temuco, se sustenta en tres causales, esto es, en el artículo 373, letra a), con dos 
órdenes de argumentos, consistentes en que los hechos dados por acreditados en el veredicto condenatorio fueron modificados en la sentencia ajustándolos a la época de vigencia de la ley penal, y en que el juez del fondo omite en su sentencia la mención y pronunciamiento jurisdiccional de todas las defensas del acusado, en los términos que exige el artículo 342, letra b), del Estatuto procedimental del ramo. En subsidio, apoya su recurso en el artículo 374, letra f), en conexión con el artículo 341, todos de la misma recopilación legal, revelando un exceso en la sentencia frente a la acusación del Ministerio Público que lo condujo a calificar el requerimiento como en blanco; $y$, en subsidio, en el artículo 373, letra b), del mencionado cuerpo normativo, con dos vertientes y argumentos diversos: La primera, consistente en que el tribunal se habría apartado de los criterios establecidos por el legislador en el artículo 14 de la Ley $N^{\circ} 20.066$, al determinar el delito y, la segunda, por cuanto la pena se reguló sobre el supuesto de un daño probable y no en el efectivamente producido.

No obstante lo anotado, refiere el quejoso que luego de la vista del recurso, el tribunal de alzada extendió su decisión con yerros de envergadura; en lo expositivo, confundieron el segundo motivo de nulidad con el segundo fundamento de la causal principal, omitieron expresar todas las causales de nulidad invocadas, no exponen aquella relativa a la infracción al principio de congruencia que adujo asilado en el artículo 374, letra f), en relación al artículo 341, del Código Procesal Penal y, no establecieron que la causal del artículo 373 , letra b), contenía doble fundamento. Asevera que la sección considerativa contiene afirmaciones inexactas, fundamentos confusos y ambiguos, y omite pronunciamiento sobre las cuestiones controvertidas en lo atingente al primer motivo subsidiario, invocado en relación al principio de congruencia, y la segunda causal subsidiaria, respecto de la cual los jueces estimaron inoficioso pronunciarse.

De este modo, afirma que los jueces de la alzada contravienen los artículos 76 y siguientes de la Constitución Política de la República y el principio de inexcusabilidad, contemplado en el artículo 10 del Código Orgánico de Tribunales.

TERCERO: Que el pronunciamiento de la Corte de Apelaciones de TemuCo, en su sección expositiva, indica que el recurso de nulidad de la defensa se sustenta en las causales de los artículos 373, letra a), 374, letra f), y 373, letra b), del Código Procesal Penal.

En su reflexión segunda, expresan los sentenciadores que el primer motivo de nulidad se basa en que se habría quebrantado el artículo 19, № 3 inciso $5^{\circ}$, de la Constitución Política de la República por cuanto habría diferencias entre el veredicto y el texto de la sentencia en cuanto a la época en que ocurrieron dos de los cuatro hechos que se tuvieron por establecidos.

En el motivo tercero indican que el segundo fundamento de la nulidad se basa en que la sentencia no se pronuncia sobre todos los argumentos de la 
defensa y que los hechos imputados constituirían un requerimiento penal en blanco que el querellante intentó completar.

El basamento cuarto refiere que la tercera motivación de nulidad se basa en que los hechos que se dieron por acreditados, en lo atinente a aquellos que determinaron la habitualidad, se apartan de los criterios legales objetivos del tipo penal del artículo 14 de la Ley $\mathrm{N}^{\circ} 20.066$.

Los tres considerandos restantes resuelven los planteamientos de la defensa al expresar en cuanto a la primera causal expuesta y a lo establecido en el artículo $19 \mathrm{~N}^{\circ} 3$ inciso $5^{\circ}$ de la Constitución Política de la República, la Defensa no justifica como se produjo esta infracción y solo se advierte que trata de vincular ésta con la causal del artículo 373 letra b) del Código Procesal Penal. Respecto del segundo argumento de la misma causal estiman que se trató de atacar los fundamentos de la defensa para los cual debió recurrir al motivo previsto en el artículo 374, letra e), lo que no hizo. Enseguida sostienen que los antecedentes deducidos como segundo motivo de nulidad no lo constituyen pues el tribunal razonó extensamente sobre la prueba rendida y los alegatos de las partes concluyendo que se han probado cuatro hechos, y aun cuando advierten una equivocación en la fecha del primero, lleva a concluir que no hay requerimiento penal en blanco y que tampoco debe el Juez pronunciarse sobre todos y cada uno de los alegatos de la Defensa, sobre todo si los hechos se encuentran acreditados. Añade que la defensa supone intensiones sin base alguna. Finalmente expresan "Que por lo expuesto anteriormente, resulta inoficioso referirse al tercer motivo de nulidad alegado".

CUARTO: Que, conforme se aprecia, el aspecto esencial por el que se decidió proceder de oficio por esta Corte, es el concerniente a la ausencia de fundamentación en la decisión que adoptaron los recurridos al resolver el rechazo del recurso de nulidad instaurado.

QUINTO: Que según ordena el artículo 384 del Código Procesal Penal, la Corte, al fallar un recurso de nulidad, debe exponer los razonamientos que sirven de base a su decisión y pronunciarse sobre las cuestiones controvertidas, salvo que acogiere el recurso, en cuyo caso podrá limitarse a fundamentar la causal o causales que le hubieren sido suficientes.

SEXTO: Que la acertada inteligencia de la norma citada permite concluir que, por imperativo legal, toda sentencia que resuelva un recurso de nulidad debe contener la enunciación y desarrollo de los razonamientos por los cuales se emite el pronunciamiento, en relación a cada uno de los asuntos sometidos a la decisión del tribunal, lo que supone la concreción de un deber fundamental del órgano jurisdiccional, que no es más que una reiteración de la obligación de los tribunales de la carga inexcusable de resolver, en todo caso, los asuntos que conozcan -artículo 10 del Código Orgánico de Tribunales. 
La omisión de pronunciamiento acerca de cualquiera de las pretensiones deducidas de manera principal o subsidiaria, vulnera necesariamente lo dispuesto en la ley, que fija con toda precisión las condiciones y el contenido de la actividad jurisdiccional, de manera que si esos presupuestos no se satisfacen, ello deviene en una manifiesta infracción a su deber fundamental.

En efecto, la aludida exigencia de motivación en las decisiones adoptadas por los órganos jurisdiccionales en torno a los recursos planteados en el nuevo sistema de enjuiciamiento criminal, constituye un requerimiento impuesto por el derecho al juicio previo, consagrado en el artículo 19, № 3, inciso quinto, de la Constitución Política de la República y en los artículos $1^{\circ}$ y 36 del Código Procesal Penal, ello como necesidad de legitimidad en este tipo de decisiones, lo que se satisface con la indicación precisa, en cada caso, de los motivos de hecho y de derecho en que se fundan las decisiones adoptadas sobre las diversas cuestiones planteadas.

En todo caso, si se compartieran los fundamentos de la decisión que se revisa, el uso del mero reenvío como técnica motivacional de la sentencia no cumple con el deber de explicitar el valor que le merecen a los sentenciadores de la Corte de Apelaciones las argumentaciones a que se remite. Un reenvío formal y general vulnera el derecho del justiciable a obtener una sentencia motivada y pone en entredicho el valor efectivo que pueda tener la doble instancia en nuestro derecho. (En este sentido, SCS Rol N 9492-09, de 26 de abril de 2010).

SÉPTIMO: Que, en este orden de ideas, basta una simple comparación entre los planteamientos formulados en el recurso de nulidad deducido y lo expresado en la resolución que denegó el referido arbitrio, para constatar que no contiene ninguna mención sobre las alegaciones esgrimidas por el quejoso acerca de una de las causales invocadas, y resuelve de modo conjunto cuestiones que motivaron causales diversas con argumentos que también difieren, de manera tal que el impugnante no está en condiciones de conocer la suerte de todos los extremos de su recurso.

OCTAVO: Que la afirmación de los recurridos sobre estos tópicos, en tanto refieren haber justificado su sentencia a través de suficientes razonamientos, basados también en la jurisprudencia de este tribunal, no es efectiva, pues no se ajusta al mérito de lo debatido, de manera que resulta fácil concluir que el dictamen no contiene todos y cada uno de los presupuestos que ordena la ley en forma precisa y determinada, es decir, las razones en las cuales se sustenta la decisión, advirtiéndose una ausencia de la adecuada fundamentación respecto de todas las causales que comprende el recurso de nulidad.

NOVENO: Que, con lo expuesto, queda establecido que los jueces de la alzada, al dictar la sentencia de siete de enero de dos mil once, cuya transcripción se acompaña a fojas 2 de este cuaderno, incurrieron en falta grave que habilita a este tribunal a hacer uso de las facultades disciplinarias y proceder de oficio, como autoriza el artículo 545 del Código Orgánico de Tribunales. 
Por estas consideraciones y de acuerdo, además, con lo dispuesto en los artículos 545 y 549 del Código Orgánico de Tribunales, PROCEDIENDO DE OFICIO, SE DEJA SIN EFECTO la resolución de siete de enero de dos mil once que falló el recurso de nulidad interpuesto en la causa RIT 1576-2010, RUC 0901036186-6, del Juzgado de Garantía de Temuco, ingresado a la Corte de Apelaciones de esa ciudad bajo el $N^{\circ}$ 962-2010, reponiéndose el procedimiento al estado que el tribunal no inhabilitado que corresponda, conozca y falle el recurso de nulidad entablado por la defensa del condenado en el referido proceso, Waldemar Andrés Cepeda Valenzuela.

Sin perjuicio de lo resuelto, la Corte de Apelaciones de Temuco deberá investigar, con la cooperación del Departamento de Informática de la Corporación Administrativa de Poder Judicial, la fecha y circunstancias en que se incorporó al sistema de registro y seguimiento de causas Siagj, la sentencia pronunciada por doña Alejandra García Bocaz, Juez Titular del Juzgado de Garantía de Temuco, correspondiente a la causa RIT 1576-2010, de ese tribunal, particularmente el hecho de si coincide con la oportunidad en que se procedió a la lectura del fallo, cuyo resultado deberá informar a esta Corte.

Se previene que la Ministra señora Egnem no comparte la indicación precedente no obstante que fue de opinión de enviar los antecedentes al Tribunal Pleno para los fines que hubiere lugar.

Se deja sin efecto la orden de no innovar concedida a fojas 32 vuelta.

Comuníquese por la vía más expedita esta resolución a la Corte de Apelaciones de Temuco y al Juzgado de Garantía de esa ciudad.

Sin perjuicio, agréguese copia autorizada al cuaderno Rol N 962-2010, de la Corte de Apelaciones de Temuco, y devuélvase en su oportunidad.

Regístrese y archívese y devuélvase su agregado.

Redacción del Ministro Sr. Juan Araya Elizalde.

Rol N 493-11.

\section{Comentario a las Sentencias}

Nos corresponde ahora referirnos a los tópicos más importantes de las resoluciones de la E. Corte Suprema recién transcritas. En todas ellas, la E. Corte Suprema conoce de oficio los antecedentes por la vía de un recurso de queja en dónde no obstante declarar inadmisible este recurso, considerando la gravedad de los hechos denunciados y el derecho involucrado fundamental, esto es, el derecho al recurso respecto de la cual el Estado chileno ha asumido compromisos internacionales, asume una actuación oficiosa a fin de cautelar debidamente el derecho aludido.

Estas sentencias son una buena excusa para abordar, aunque sea con todas las limitaciones propias de un comentario jurisprudencial, algunos de los puntos 
que, según nuestro parecer, resultan ser fundamentales para volver a insistir sobre la lógica y principios que están detrás del modelo de enjuiciamiento penal en general y del modelo impugnativo en particular, con protagonismo excluyente del recurso de nulidad, respecto de los cuales, a estas alturas del avance y consolidación de la reforma debiera existir un mejor grado de comprensión por los distintos operadores, en especial de parte de nuestros tribunales de justicia.

Concretamente, a partir de las sentencias de la E. Corte Suprema revisaremos la concepción que de los recursos se recoge en el modelo de enjuiciamiento penal reformado que nosotros entendemos supera su entendimiento tradicional como un mecanismo de control jerárquico para dar paso a su entendimiento como un mecanismo de garantía de los justiciables contra la arbitrariedad y errores que puedan cometer los tribunales en su actividad de sentenciar. A partir de esta base analizaremos y vincularemos el deber de fundamentación y principio de contradicción que rigen respecto del recurso de nulidad y que están Ilamadas a llenar de contenido el derecho al recurso antes referido.

1. Giro desde los recursos concebidos como un mecanismo de control jerárquico, al recurso concebido como una garantía judicial mínima y, sobre todo, un derecho de parte, en especial, del imputado

No hay dudas que el juicio oral es el eje fundamental en torno al cual gira el sistema de justicia criminal que recoge nuestro Código Procesal Penal (CPP). Si bien su procedencia está reservada para ciertos casos, sus principios y reglas fundamentales (contradicción, inmediación, oralidad y publicidad), son transversales a todo el proceso, en cualquiera de sus etapas. Así y ya a una década del inicio de la reforma, vale la pena traer a colación algunos aspectos del relevante debate planteado en relación a la determinación del sistema recursivo que el CPP recogería, pues se debían respetar los compromisos internacionales que Chile había adquirido en relación a la garantía del "derecho al recurso".

Si bien en la discusión pre-legislativa existieron voces que plantearon la inconveniencia de prescindir del protagonismo del recurso de apelación ${ }^{1}$, la opción legislativa finalmente estuvo clara desde sus inicios. Por ello, el mensaje del CPP, manifiesta que la concepción básica del sistema recursivo en el nuevo sistema de justicia criminal, implicaba un cambio radical en la configuración de los controles que el proceso penal tenía durante la vigencia del Código de Procedimiento Penal de 1906 (C. de PP), el que se basaba fundamentalmente en un control vertical que ejercían los tribunales superiores respecto de los jueces de la instancia², a partir

\footnotetext{
'Véase: Pereira Anabalón, H., "Oralidad e instancia única o doble en el proceso penal", Revista Gaceta Jurídica №233, 1999.

${ }^{2} \mathrm{Al}$ respecto, el modelo inquisitivo vigente durante casi cien años, establecía como recurso fundamental, la apelación, la cual tenía cabida contra toda resolución judicial dictada en contra del que se consi-
} 
de lo cual el recurso se configuraba más como un medio de control jerárquico, que en un derecho de parte, y en específico una garantía.

Ahora bien, teniendo a la vista la centralidad que se reconocía al juicio oral, y en especial a sus principios y reglas fundamentales, destacadamente la inmediación y la oralidad, se señaló desde un comienzo que el establecer un sistema de recursos configurado sobre la base de la concepción ligada al control jerárquico, era absolutamente contrario a un modelo procesal penal en donde dichos controles, que deben existir, se deben ejercer de un modo horizontal entre los intervinientes, considerados sujetos procesales.

Coherentemente con este planteamiento considerado fundamental, el sistema de recursos que contempla nuestro CPP fue configurado a partir del juicio oral como elemento central, etapa procesal en donde de mejor modo podían ser desarrolladas las garantías mínimas del debido proceso ${ }^{3}$, sin desatender que dicha instancia se configura como principio supremo del sistema a partir de lo dispuesto en el artículo $1^{\circ}$ del CPP ${ }^{4}$.

De este modo, y al hilo de lo que se está explicando, los recursos se estructuran en el CPP: 1) como medios de impugnación de parte, lo que es una consecuencia de los principios de contradicción e imparcialidad del tribunal ${ }^{5}$;

derara agraviado por ella. Ello restaba valor a lo decidido por el juez de la instancia, pues el tribunal superior, dado su intenso control, podía revisar todo lo actuado y no realizado por el inferior, pudiendo extender su competencia más allá de lo solicitado en el recurso. Un segundo dato, que demuestra la intensidad vertical de control, era la existencia de una institución denominada "la consulta", la cual, bastante criticada por la dogmática, constituyó el paradigma de modelo procesal inquisitivo de control del superior, respecto de los tribunales inferiores.

${ }^{3}$ Bachmaier Winter, Lorena, "Acusatorio versus Inquisitivo. Reflexiones acerca del proceso penal", en Proceso Penal y Sistemas Acusatorios, Marcial Pons, Madrid 2008, p. 37. Quién, sin perjuicio de las críticas formuladas al Ilamado "principio acusatorio", indica que: "El juicio oral es el acto primordial del proceso en el cual se refleja el paradigma del modelo acusatorio que, (...) consiste en el enfrentamiento de dos partes en posición de igualdad ante un juez imparcial. Ese tribunal imparcial como regla, sólo puede fundar la sentencia en lo alegado y probado por las partes en el juicio público, oral y contradictorio".

${ }^{4}$ Al respecto, Tavolari Oliveros, Raúl, Instituciones del Nuevo Proceso Penal. Cuestiones y Casos, Editorial Jurídica de Chile, Santiago de Chile 2005, pp. 200 y 201, quién sostiene al analizar el recurso de nulidad y el control fáctico que puede realizar el tribunal que conoce de él: "Para analizar la situación producida, es indispensable, a riesgo de la obviedad, reiterar que el sistema del Código Procesal Penal comprende, como suprema garantía de enjuiciamiento, la substanciación de un 'juicio previo oral y público'. Esta condición de piedra angular que asume el juicio, se confirma de múltiples formas y en función de diversas disposiciones. Así, es central la declaración contenida en el art. $1^{\circ}$ de dicho Código, con arreglo al cual toda persona tiene derecho a un juicio previo, oral y público".

${ }^{5}$ Horvitz Lennon, María Inés; López MAsLe, Julián, Derecho Procesal Chileno, T. II, Editorial Jurídica de Chile, Santiago 2004, p. 350. Por su parte, la jurisprudencia de la E. Corte Suprema ha desarrollado una doctrina en tal sentido, en cuanto a que entiende que los recursos en el nuevo sistema de justicia criminal no son un medio de control jerárquico sino un medio de impugnación de parte. Así, el considerando quinto de la sentencia de fecha 17 de junio de 2010, Rol: 1123-2010, indica que: [...] En efecto, el tribunal superior sólo puede revisar los puntos de hecho y de derecho considerados en la resolución y que hayan sido impugnados a través del recurso..., [...] La norma en análisis contiene, entonces, una 
y, 2) como lo han postulado en su reconocido texto López y Horvitz ${ }^{6}$, en un modelo que claramente disminuye la intensidad del régimen de los recursos, lo que conlleva que éstos sean procedentes en menos ocasiones, o sólo en determinados casos.

Así, resulta improcedente la apelación en contra de las resoluciones dictadas en un juicio oral, toda vez que los recursos no se asocian a una nueva instancia, pues ello, se dijo y dice, sería contrario a la inmediación y la oralidad, que como se indicara antes se consideran los principios y reglas centrales del juicio oral ${ }^{7}$. Ello explica, se ha sostenido por la doctrina, que la sentencia que se dicte por el Tribunal del Juicio Oral en lo Penal (en adelante TJOP) sea impugnable únicamente por el recurso de nulidad y por los motivos taxativos que expresamente señala el legislador ${ }^{8}$.

Conforme con ello, seguimos aquí dando cuenta de las razones tenidas a la vista a la hora de diseñar el sistema impugnativo del nuevo modelo de enjuiciamiento penal, el recurso de nulidad se configuró como un mecanismo extraordinario que claramente limita al ámbito de cognición del tribunal superior que, a diferencia de lo que acontece con el recurso ordinario de apelación, queda reducido al examen de los motivos previstos expresamente en la ley y que las partes hayan invocado. Esta reducción competencial del tribunal que debe conocer del recurso de nulidad impone, además, que el debate autorizado deba respetar la regla de la intangilidad de lo fáctico.

severa limitación a las otrora más amplias facultades que les otorgaba a los jueces un sistema procesal inquisitivo. Con ella, precisamente, se impide a los jueces resolver ultra petita, término utilizado por el legislador en la discusión parlamentaria al respecto -así lo recuerda Emilio Pfeffer en su Código Procesal Penal Anotado y Concordado, 2a ${ }^{\text {a }}$ Edición, pág. 540- lejos del terreno del recurso de casación, como se argumenta en el informe correspondiente, sino como énfasis en lo que la norma veda: no extender el efecto de la decisión en los recursos que autoriza a cuestiones, o, como lo entiende nuestro léxico, a los puntos, asuntos o materias dudosas o discutibles propuestas en un debate y que deben ser resueltas, en clara correspondencia con los fundamentos de lo pedido, o más allá de sus límites (PFEFFEr, Emilio, Código Procesal Penal Anotado y Concordado, 2 2a Edición, Editorial Jurídica, Santiago de Chile p. 540). Por voluntad legislativa, se contemplaron escasas excepciones en la misma disposición, pero ellas no vienen más que a confirmar la regla general. Consiguientemente, la norma en cuestión resulta ser absolutamente coherente con el nuevo sistema procesal penal y no se produce lo contrario, como también se informa. En el mismo sentido: sentencias de la E. Corte Suprema, de fecha 14 de julio de 2010, Rol 4972-2010, considerando séptimo, y sentencia de fecha 26 de agosto de 2010, Rol 4645-2010, considerandos 3 y 4.

${ }^{6}$ Horvitz; López, Derecho, cit. nota n. 5, p. 352. En el mismo sentido, Carocca Pérez, Álex, Manual El nuevo Sistema Procesal Penal, LexisNexis, Santiago de Chile 2005, p. 268, para quien el rol central del nuevo sistema de recursos lo desempeña el recurso de nulidad, teniendo una menor incidencia el recurso de apelación.

${ }^{7}$ Así el artículo 364 del CPP dispone: Serán inapelables las resoluciones dictadas por un tribunal de juicio oral en lo penal.

${ }^{8}$ Como indica Pfeffer, pueden agruparse en dos grandes causales genéricas: "la vulneración de derechos o garantías, y a la errónea aplicación del derecho con influencia sustancial en lo dispositivo del fallo". Pfeffer, Código Procesal Penal, cit. nota n. 5, p. 369. 
Según lo expuesto, existe una evidente tensión de cuya existencia dan cuenta las sentencias que han emanado de nuestros tribunales en lo que va de reforma. En efecto, por una parte, se reconoce el derecho al recurso y, por otra, se le limita o minimiza con el fin de mantener y tutelar la centralidad de lo que genera el juicio oral en el modelo de enjuiciamiento penal. A nuestro juicio, en un contexto jurisprudencial dónde se ha instalado un criterio restrictivo o el contenido de los derechos asociados al "derecho al recurso" se relaja en su estándar de satisfacción, esta situación de tensión antes aludida podría suponer, en la realidad del foro, terminar negando la garantía del "derecho al recurso" (con reconocimiento internacional) ${ }^{9}$, más allá de lo declarado en reiteradas oportunidades por un sector de la doctrina nacional en orden a defender el ajuste del recurso de nulidad con esta garantía invocando al efecto "la regla de la doble conforme ${ }^{\prime 10}$. Al contrario, superando el tono dogmatizador de algunos, cada vez es más frecuente escuchar fundadas opiniones que, atendiendo lo que ha venido mostrando la realidad funcional de nuestro sistema impugnativo, inciden justamente en el problema de compatibilidad del recurso de nulidad en relación con las exigencias derivadas del "derecho al recurso"11.

Atrás parecen haber quedado las razones que se daban para justificar la configuración de la nueva protagonista del sistema recursivo en sede procesal penal. Las alusiones realizadas al establecimiento de un mecanismo de impugnación amplio, no sujeto a demasiados rigores formales, que no padecía los tradicionales problemas del recurso de casación y que desde luego, cumplía con la garantía de acceso al recurso, parecen perder asidero cuando se analiza cuál ha sido el desempeño del recurso en la práctica durante estos años. Se ha coincidido en denunciar la irrupción de un criterio muy restrictivo, sumado a un excesivo rigor

\footnotetext{
${ }_{9}^{9}$ Con reconocimiento, por ejemplo, en la Convención Americana de Derechos Humanos (artículo 8. 2 letra h) y en el Pacto Internacional de Derechos Civiles y Políticos (artículo 14.5).

${ }^{10}$ Véase: Duce J, Mauricio; Riego R., Cristian, Proceso Penal, Editorial Jurídica de Chile, Santiago 2007, p. 515; HoRvitz; LÓPEZ, Derecho, cit. nota n. 5.

${ }^{11}$ Horvitz sostiene: "[...] es claro que el recurso de nulidad establecido en el Código Procesal Penal y previsto como único medio de impugnación de las sentencias recaídas en juicios orales no satisface los estándares sobre debido proceso elaborados por el derecho convencional internacional, la doctrina y la jurisprudencia y, en particular, el derecho al recurso. En efecto, se trata de un recurso extraordinario y restrictivo, cuyos requisitos de admisibilidad han sido interpretados de forma aún más estrecha por la jurisprudencia, situación que ha determinado que en muy pocas ocasiones ellos sean acogidos, no existiendo -además- recurso alguno en contra de la resolución que se pronuncia sobre un recurso de nulidad (art. 387 inc. 1 CPP). Por ello, no está en condiciones de satisfacer el objetivo de permitir la revisión más amplia posible de la sentencia, menos cuando su origen se halla en la casación que, tradicionalmente, se vincula a la idea de remedio impugnatorio limitado. Claro que en esa misma tradición, ella procede contra la sentencia de segunda instancia, esto es, después de una revisión amplia (apelación) de la decisión de primer grado. Horvitz LenNON, María Inés, "Acerca de la garantía del condenado de recurrir en contra de la sentencia condenatoria", Informes en derecho, doctrina procesal penal 2008, Centro de Documentación Defensoría Penal Pública, № 6, 2008, p. 24.
} 
formal como notas distintivas del recurso de nulidad, materializándose en los tribunales que deben conocerlo y fallarlo una interpretación divorciada de la genuina concepción del recurso que, desde luego, atenta contra la garantía del derecho al recurso ${ }^{12}$. Entre las razones que se han expresado para justificar estos criterios restrictivos y rigorismos formales están el tratarse de un recurso extraordinario, de derecho estricto, en dónde la elevación de los requisitos formales está en función de asegurar la excepcionalidad del recurso de nulidad ${ }^{13}$, todo ello, además, sumado a la permanente advertencia de que a través de este recurso no es posible inmiscuirse en las cuestiones de hecho establecidas por el tribunal de la instancia, dado que lo contrario implicaría frustrar la finalidad misma para la que fue instaurada la inmediación judicial, perdiéndose la posición privilegiada del tribunal del juicio oral.

La relevancia del tema es evidente. Sus graves consecuencias para los justiciables también. Es que la cuestión de cómo los tribunales llenan de contenido esta garantía del derecho al recurso no es baladí desde la perspectiva de determinar si se está o no satisfaciendo con lo que impone la garantía en comento, más aún tras el papel que han cumplido los Tratados internacionales de Derechos Humanos en la concreta configuración del perfil moderno del debido proceso en general y del derecho al recurso en particular (baste citar el emblemático caso Herrera Ulloa vs Costa Rica ${ }^{14}$, ante la Corte Interamericana de Derechos Humanos), a partir de los cuales se ha reiterado que independientemente de la denominación del recurso existente para impugnar un fallo, lo importante es que dicho recurso cumpla con determinados estándares y garantice un examen

\footnotetext{
${ }^{12}$ Cortéz Matcovich, G., El recurso de nulidad: doctrina y jurisprudencia, LexisNexis, Santiago, 2006, pp. 39-52

${ }^{13}$ La E. Corte Suprema en sentencia de fecha 30 de enero de 2008, Rol 6764-2007, que rechazó un recurso de nulidad de la defensoría penal pública, indica en su considerando quinto que: "[...] en relación a los fundamentos del recurso, es preciso tener en cuenta lo que ha expresado esta Corte Suprema en relación al referido recurso al decir que conceptualmente es un medio de impugnación legal en favor de los intervinientes del juicio oral en razón de especial agravio que les provoca la sentencia o su tramitación al infringirse sustancialmente derechos o garantías asegurados por la Constitución por los tratados internacionales ratificados por Chile y vigentes, se cometa una errónea aplicación del derecho con influencia sustancial en lo dispositivo del fallo, se incurriera en algún motivo absoluto de nulidad expresamente reconocido por la ley, con el objeto que la respectiva Corte de Apelaciones o, excepcionalmente, la Corte Suprema cuando ello corresponda, anule el juicio oral y la sentencia definitiva o solamente ésta. Se desprende de lo dicho que sus características fundamentales corresponden a un recurso extraordinario y de derecho estricto, en razón de los cuales se persigue la invalidación de la sentencia o del juicio oral o de ambos, sólo por causales expresamente definidas en la ley cumpliendo, además, algunas formalidades legales [...]. De lo transcrito se concluye que se trata de un recurso de carácter extraordinario, de derecho estricto y que las infracciones que se denuncien deben ser de tal naturaleza que hagan variar sustancialmente lo que se ha resuelto en el fallo". En el mismo sentido pueden leerse otras sentencias: 1) de 12 de mayo de 2003, Rol 964-03, considerando segundo, y 2) de 30 de enero de 2008, Rol 5956-2007, considerando séptimo.
}

${ }^{14}$ Sentencia de 2 de julio de 2004 (Corte Interamericana de Derechos Humanos). 
integral de la decisión recurrida sobre la base del análisis de todas las cuestiones debatidas en el tribunal inferior.

Así las cosas, se ha considerado que el derecho al recurso ante el tribunal superior debe ser una reconsideración de tendencia general de las cuestiones de hecho y de derecho (meritum causae) y no sólo una querella nullitatis. En otras palabras, se ha resaltado que la eficacia del recurso se encuentra estrechamente vinculada con el alcance de la revisión. Esto, debido a que la falibilidad de las autoridades judiciales y la posibilidad de que cometan errores que generen una situación de injusticia no se limita a la aplicación de la ley, sino que incluye otros aspectos tales como la determinación de los hechos o los criterios de valoración probatoria. De esta manera, el recurso será eficaz para lograr la finalidad para el cual fue concebido, si permite una revisión sobre tales cuestiones sin limitar a priori su procedencia a determinados extremos de la actuación de la autoridad judicial. ¿Está nuestro recurso de nulidad satisfaciendo este estándar? La respuesta negativa parece sobrar, por evidente.

Por lo señalado hasta acá es que la sentencia de nulidad que rechaza este recurso no realice una adecuada fundamentación es una práctica de algunos tribunales que resulta imposible de tolerar desde el momento que vacía de contenido la garantía del derecho al recurso y el carácter del doble conforme, que un Estado democrático de derecho reconoce al justiciable. En este sentido, no podemos sino compartir lo razonado por la E. Corte Suprema en la sentencia Rol $N^{\circ}$ 9492-2009, que es objeto de este comentario, cuando indica que: "[E]I uso del mero reenvío como técnica motivacional de la sentencia no cumple con el deber de explicitar el valor que le merece al sentenciador de segunda instancia las argumentaciones a que se remite. Un reenvío formal y general vulnera el derecho del justiciable a obtener una sentencia motivada y pone en entredicho el valor efectivo que pueda tener la doble instancia en nuestro derecho" ${ }^{\prime 15}$.

Dicha sentencia recoge, a nuestro juicio, una interpretación adecuada, en orden a exigir a los tribunales superiores que conocen del recurso de nulidad, el deber de resolver aquellos asuntos sometidos a su conocimiento, vinculando dicha exigencia con la inexcusabilidad contemplada en el artículo 10 del Código Orgánico de Tribunales (considerando quinto de la sentencia Rol № 2511-2009), todo lo cual refuerza y como indicábamos materializa la garantía del "derecho al recurso", puesto que de nada serviría en realidad reconocerla, si la resolución de nulidad se bastara con el mero reenvío formal a la sentencia impugnada, sin resolver los planteamientos que el recurrente impugna.

${ }^{15}$ En el mismo sentido pueden leerse otras sentencias de la E. Corte Suprema: 1) de fecha 12 de julio de 2010, Rol 1168-2010, considerando sexto, y, 2) de fecha 28 de febrero de 2011, Rol 493-2011, considerando sexto. 
2. Del contenido de la sentencia que rechaza el recurso de nulidad. Fundamentación y contradictoriedad, como forma de materializar la garantía del "derecho al recurso"

Hemos señalado que el sistema recursivo que consagra el CPP contempla un solo recurso capaz de atacar la sentencia dictada por el TJOP. Este recurso (de nulidad) tiene causales de derecho estricto, y su regulación lo ha hecho ser abordado como un recurso excepcional, tal cual ha quedado de manifiesto en la aplicación que del mismo han realizado los tribunales.

Al contrario de lo que ha sido la práctica de algunos tribunales superiores en relación con este recurso, consideramos que su configuración legal ya limitada impone a los operadores de este modelo una interpretación que se aproxime en la mayor y mejor medida posible a permitir el adecuado ejercicio del derecho que le asiste al enjuiciado para recurrir contra un fallo que le sea desfavorable ${ }^{16}$. En consecuencia, no debe considerarse suficiente posibilitar que el condenado pueda recurrir en contra de una sentencia que le es desfavorable, sino que también debe considerarse necesario que la sentencia que resuelve el recurso, deba resolver las causales y los motivos de nulidad denunciados, de modo tal, que el fallo condenatorio y la pena impuesta puedan respetar la garantía del juicio previo contenida en el artículo $1^{\circ}$ del CPP, puesto que de nada serviría garantizar la facultad de recurrir, si dicho recurso no fuera resuelto mediante una sentencia que fundadamente resuelva el debate y la controversia.

Lo anterior liga estrechamente con la fundamentación de las resoluciones judiciales, labor exigible a la actividad jurisdiccional en un Estado democrático de derecho, y el principio de contradicción, que implica que nadie pueda ser condenado sin ser oído ${ }^{17}$.

- Fundamentación y contenido de la sentencia que falla el recurso de nulidad

Como contrapartida al sistema de libertad probatoria que se recogía, el CPP estableció un estricto sistema de fundamentación de las resoluciones judiciales ${ }^{18}$.

\footnotetext{
${ }^{16}$ En esta materia, el intérprete debe tener presente lo que dispone el inciso 2 del artículo $5^{\circ}$ del CPP, el cual dispone: "Las disposiciones de este Código que autorizan la restricción de la libertad o de otros derechos del imputado o del ejercicio de alguna de sus facultades serán interpretadas restrictivamente y no se podrán aplicar por analogía".

${ }^{17}$ Sobre el tema véase: Montero Aroca, Juan; Gomes-Colomer, Juan Luis; Monton Redondo, Alberto; Barona VILAR, Silvia, Derecho Jurisdiccional, Tomo III, Editorial Tirant lo Blanch, Valencia, 2001, pp. 27 a la 29. Montero Aroca, Juan, "Principio Acusatorio y Prueba en el Proceso Penal. La inutilidad jurídica de un eslogan político", en Prueba y Proceso Penal. Análisis especial de la prueba prohibida en el sistema español y en el derecho comparado, Editorial Tirant lo Blanch, Valencia 2008, pp. 17 y ss.; Bovino, Alberto, Principios Políticos del Procedimiento Penal, Editores del Puerto, Buenos Aires Argentina 2005, pp. 37 y ss.

${ }^{18}$ En este sentido, vale la pena tener en cuenta el mensaje con que el Ejecutivo envió al Congreso el proyecto de CPP, que señala: "Paralelamente al reconocimiento de la libertad del juez para la valoración de la prueba, se enfatiza la necesidad de la explicitación de los razonamientos utilizados para el
} 
Así, en el artículo 36 del CPP, el cual contiene una norma de contenido general, dispone por primera vez en nuestro sistema procesal penal que: "Será obligación del tribunal fundamentar las resoluciones que dictare, con excepción de aqueIlas que se pronunciaren sobre cuestiones de mero trámite. La fundamentación expresará sucintamente, pero con precisión, los motivos de hecho y de derecho en que se basaren las decisiones tomadas. La simple relación de los documentos del procedimiento o la mención de los medios de prueba o solicitudes de los intervinientes no sustituirá en caso alguno la fundamentación".

Esta norma tiene su correlato en los artículos 297, 342 letra c y d del CPP, todos los cuales imponen el deber de fundamentar las resoluciones y sentencias dictadas por los tribunales de justicia en el ámbito penal. En este sentido, la doctrina ha indicado que "el CPP chileno ofrece una regulación excepcionalmente detallada del contenido de la fundamentación legal del juicio de hecho", lo que además de constituir una ventaja en relación al antiguo sistema procesal, incluso, sería una ventaja por sobre otras legislaciones ${ }^{19}$.

La E. Corte Suprema ha exigido dicha fundamentación tanto en las sentencias comentadas (considerando décimo y undécimo de la sentencia Rol $N^{\circ}$ 9492-2009) como en otras tantas, percibiéndose que se ha ido exigiendo una adecuada fundamentación de las conclusiones. Así anotamos a los fines de estas reflexiones las sentencias siguientes: 1 ) de fecha 26 de enero de 2009, Rol 5898-2008, considerando cuadragésimo octavo, 2) de fecha 22 de abril de 2009, Rol 1208-2008, considerando noveno, y 3) de fecha 23 de diciembre de 2009, Rol 6934-2009, considerandos decimoquinto, decimosexto, entre otras.

En este riguroso esquema de fundamentación que se impone (coherentemente) en el reformado modelo de enjuiciamiento penal, el artículo 384, prescribe: "en la sentencia, el tribunal deberá exponer los fundamentos que sirvieren de base a su decisión; pronunciarse sobre las cuestiones controvertidas, salvo que

establecimiento de los hechos a partir de diversos medios. Esta fundamentación debe constituirse en una de las exigencias más rigurosas para los jueces como único modo de garantizar el posterior control de sus decisiones, tanto por parte de los tribunales que conozcan de los recursos en contra de la sentencia como por parte del conjunto de la sociedad." Mensaje del Ejecutivo a la Cámara de Diputados de LA República, Código Procesal Penal, Editorial Jurídica de Chile, 4 Edición, 2006, pp. 39 y 40.

${ }^{19}$ Accatino Scagliottı, Daniela, "El Modelo Legal de Justificación de los Enunciados Probatorios en la Sentencia Penal y su control a través del Recurso de Nulidad", en Formación y Valoración de la Prueba en el Proceso Penal, Editorial Abeledo Perrot Legal Publishing, 2010, p. 121 y siguientes. En el mismo sentido, en: AcCatino SCAGlottı, Daniela, "La fundamentación de la declaración de hechos probados en el nuevo proceso penal. Un diagnóstico", Revista de Derecho Vol. XIX, № 2 (Universidad Austral de Chile), 2006, p. 9-26. La autora sostiene que: "Las normas legales antes indicadas parecen dar acogida en nuestra legislación a la más avanzada interpretación doctrinal comparada de la exigencia de motivación de los enunciados probatorios, que defiende un modelo de justificación -que algunos autores denominan "analítico"- que requiere una exposición pormenorizada de todas las pruebas practicadas, del valor probatorio que se les ha asignado y las razones que lo sustentan y de la cadena de inferencias que permite tener por justificadas las conclusiones probatorias". 
acogiere el recurso, en cuyo caso podrá limitarse a la causal o causales que le hubieren sido suficientes, y declarar si es nulo o no el juicio oral y la sentencia definitiva reclamados, o si solamente es nula dicha sentencia, en los casos que se indican en el artículo siguiente" (en los que se dicte una sentencia de reemplazo). En este orden de ideas, el Código Procesal Penal establece que la sentencia que acoge el recurso deberá fundamentar la causal por la cual acoge el recurso, pudiendo omitir las restantes, lo que se condice con la garantía del derecho al recurso, pues el enjuiciado no verá amagado su derecho a que los motivos por los cuales impugna una sentencia no sean arbitrariamente desechados. Cosa distinta es la que sucede en el caso de que el recurso sea rechazado, pues en tal caso, la resolución que falla el recurso rechazándolo debe expresar los fundamentos por los cuales rechaza el recurso. Esto no es sino otra consecuencia de lo dispuesto en el artículo 36 del CPP.

Así las cosas, las sentencias comentadas interpretan el artículo 384 del CPP, como una norma que exige que la sentencia del recurso de nulidad "por imperativo legal (...) debe contener la enunciación y desarrollo de los razonamientos por los cuales se emite el pronunciamiento en relación a cada uno de los asuntos sometidos a la decisión del tribunal, lo que supone la concreción de un deber fundamental del órgano jurisdiccional que no es más que una reiteración de la obligación de los tribunales de la carga inexcusable de resolver, en todo caso, los asuntos que conozcan, artículo 10 del Código Orgánico de Tribunales. La omisión de pronunciamiento sobre una de las pretensiones deducidas vulnera necesariamente lo dispuesto en la legislación, que fija con toda precisión las condiciones y el contenido de su actividad, de manera que, si esos presupuestos no se satisfacen, deviene en una manifiesta infracción a su deber público fundamental" (considerando quinto, sentencia Rol № 2511-2009) ${ }^{20}$.

Consideramos que lo resuelto por la E. Corte Suprema constituye un importante avance en la dirección correcta, pues el deber de fundamentación no solo será una exigencia para la sentencia del TJOP o el tribunal de la instancia, sino que también para los tribunales de nulidad. Bien señalaba Accattino: "una consecuencia del establecimiento de la exigencia general de fundamentación [...], es que ella hace necesaria la expresión de razones también respecto de las sentencias dictadas por las Cortes de Apelaciones y por la Corte Suprema al conocer de algún recurso. La extendida práctica anterior a la reforma del 'Vistos, se confirma' -amparada en la antigua legislación procesal penal- debiera, por consiguiente, haber desaparecido" 21 .

\footnotetext{
${ }^{20}$ En el mismo sentido: considerando duodécimo a decimoquinto de la sentencia Rol 9492-2009, sentencia materia de este comentario; considerandos sexto a octavo, sentencia de la E. Corte Suprema de fecha 12 de julio de 2010, Rol 1168-2010, y considerando cuarto a sexto, sentencia de la E. Corte Suprema de fecha 28 de febrero de 2011, Rol 493-2011.
}

${ }^{21}$ AcCatino, "La fundamentación", cit. nota n. 19, p. 12, cita al pie № 6. 
Tal como indican las sentencias comentadas, este deber de fundamentación de la sentencia que falla el recurso que emana del artículo $19 \mathrm{~N}^{\circ} 3$ de la Constitución Política de la República, "no se satisface con meras referencias formales al hecho de haberse cumplido los estándares legales o a la existencia de antecedentes generales invocados".

Siendo la fundamentación de las resoluciones judiciales una garantía para el imputado, tal como lo expresan las sentencias comentadas, ello no sólo materializa la garantía del derecho al juicio previo, sino también la garantía del derecho al recurso, al ser "un derecho del justiciable el reexamen de la cuestión sometida a decisión ante jueces distintos" (considerando décimo quinto sentencia Rol $N^{\circ}$ 9492-2010). Así, el deber de motivar las sentencias es un componente esencial del modelo de jurisdicción propio de un Estado democrático de derecho ${ }^{22}$.

Finalmente, corresponde señalar que de acuerdo a lo expuesto, la fundamentación debe estar referida a todas las causales esgrimidas cuando el recurso fuera rechazado. Vale la pena considerar que conforme lo dispone el CPP en su artículo 378 inciso $2^{\circ}$, el recurso puede contener varias causales, y estas varios motivos que configuran la causal. Así por ejemplo, el primer fallo (que tiene como Rol el No 2511-2009), tiene como causal la contenida en el artículo 373 letra a) del CPP, respecto de infracción de garantías, causal que contiene distintos motivos de nulidad, como son por ejemplo, la falta de un tribunal imparcial, la imposibilidad de producir prueba de descargo, entre otros. Al respecto, el máximo tribunal entiende acertadamente que cada motivo de nulidad debe ser resuelto en el fallo de nulidad.

En este mismo orden de cosas, no deja de avalar lo sostenido, cuando el artículo 360 del CPP, indica que: "el tribunal que conociere de un recurso sólo podrá pronunciarse sobre las solicitudes formuladas por los recurrentes". Así, toda solicitud planteada debe ser resuelta por el fallo de nulidad, lo cual no hace más que acentuar el carácter contradictorio que la Corte Suprema le ha dado al proceso penal chileno como se indicará a continuación, lo cual como hemos venido indicando, materializa entre otras, la garantía del "derecho al recurso".

- Contradictoriedad y fallo de nulidad

El artículo 384 del CPP se relaciona directamente con el artículo 360 del CPP, que en su inciso primero, fija la competencia de los tribunales superiores para conocer de los recursos de nulidad y apelación, estableciendo una competencia, centrada únicamente a lo que las partes sometan a decisión del tribunal. Esto tiene que ver con el carácter contradictorio del sistema criminal, lo cual la E. Corte Suprema ha

\footnotetext{
${ }^{22}$ En este sentido, resulta relevante, por más que aparezca reiterativo, lo resuelto por la sentencia de la E. Corte Suprema con fecha 24 de agosto de 2010, la cual señala en su considerando vigésimo sexto: "Que la nueva legislación procesal penal ha sido especialmente exigente en orden a imponer a los jueces que conocen y resuelven en definitiva en juicio oral un trabajo de elaboración meticuloso y cuidadoso en la confección de sus sentencias".
} 


\section{recalcado en variados fallos, estableciendo una doctrina uniforme que tiene un carácter transversal en variados asuntos como: 1) la actividad probatoria $\left.{ }^{23}, 2\right)$ los poderes o facultades del tribunal ${ }^{24}$, y 3 ) en materia recursiva ${ }^{25}$.}

${ }^{23} \mathrm{Al}$ respecto, la sentencia de la E. Corte Suprema de fecha 26 de septiembre de 2006, Rol 3795-2006, que
acoge un recurso de nulidad de la defensa indica en su considerando décimo tercero: "que, en el principio
de contradicción se ha incluido, tradicionalmente, el derecho de probar y el de controlar la prueba del
adversario. Ello no es incorrecto, pues, sobre todo el control de la prueba del adversario, representa una
manifestación del contradictorio, a la vez que la facultad otorgada para demostrar los extremos que son
esgrimidos para inhibir la imputación de que se es objeto, o aminorar sus consecuencias, es una manifes-
tación imprescindible de la posibilidad de oponerse a la ejecución penal. Sin embargo, esas facultades
se explican mejor en función del ideal de equiparar las posibilidades del imputado respecto de las del
acusador, máxima que también integra la garantía de la defensa y que se denomina igualdad de posiciones (Julio Maier, Derecho Procesal Penal, I. Fundamentos, págs. 577 y ss.)".

${ }^{24}$ En este sentido, sentencia de la E. Corte Suprema que acoge el recurso de nulidad de la defensoría penal pública de fecha 12 de noviembre de 2008, Rol 4954-2008, la cual en su considerando noveno, dispone: "Que es necesario recordar en esta parte que el artículo 361, ubicado en el Título I de las disposiciones generales de los recursos, prescribe que éstos se rigen por las normas de ese libro y en forma supletoria, lo serán por las del Título III del Libro Segundo de ese Código. El Libro II, Título III, es el que señala las normas que rigen el juicio oral, de modo que no corresponde hacer aplicación supletoria de las prescripciones del Código de Procedimiento Civil. En este sentido, la revisión de cada una de las disposiciones del señalado título permiten concluir sin lugar a dudas que la iniciativa probatoria nunca es del juez, sino siempre de las partes, quienes tienen completa libertad para demostrar los hechos y circunstancias pertinentes para la adecuada solución del caso sometido a enjuiciamiento.

Por último, el artículo 360, relativo a las decisiones de los recursos, circunscribe el pronunciamiento del tribunal exclusivamente a las solicitudes formuladas por los recurrentes, quedándole vedado extender el efecto de su decisión a cuestiones no planteadas por ellos o más allá de los límites de lo solicitado.

De todo lo expresado, es posible extraer como conclusión, que la Corte de Apelaciones cuando conoce del recurso deducido por el Ministerio Público contra el auto de apertura por la exclusión de pruebas determinadas por el Juez de Garantía, debe limitarse a escuchar los hechos y argumentos que las partes le exponen y los antecedentes que ya obren en la carpeta que ha recibido. Cualquier duda que se le presente puede salvarla de inmediato, ante las mismas partes, por cuanto todo lo expresado, es posible extraer como conclusión, que la Corte de Apelaciones cuando conoce del recurso deducido por el Ministerio Público contra el auto de apertura por la exclusión de pruebas determinadas por el Juez de Garantía, debe limitarse a escuchar los hechos y argumentos que las partes le exponen y los antecedentes que ya obren en la carpeta que ha recibido. Cualquier duda que se le presente puede salvarla de inmediato, ante las mismas partes, por cuanto ello tiene el objeto que lo dicho por una de ellas pueda ser siempre conocido por la otra y controvertido o complementado, en su caso.

Esta es la forma en que, actualmente, se conoce la apelación de un proceso penal. El tribunal no pide pruebas, no dispone oficiosamente la práctica de ninguna diligencia probatoria, ni para mejor resolver, puesto que la naturaleza propia de éstas cual sería la de las contempladas en el artículo 159 del Código de Procedimiento Civil es precisamente agregar antecedentes probatorios o datos que no habían quedado suficientemente satisfechos. En la reforma penal, las dudas del tribunal deben ser satisfechas por las partes, en este proceso, fiscal y/o querellante en su caso, y defensor. Ellos deben poner en conocimiento del tribunal todos sus argumentos y plantear los hechos de forma acabada y suficiente para que el tribunal quede bien informado sobre aquello que ha sido sometido a su conocimiento, de modo que de subsistir cualquier duda o de haber verificado alguna inexactitud, el tribunal pregunta a las mismas partes, en la audiencia, sobre lo que le ha resultado oscuro o desconocido.

Esta forma de llevar adelante la audiencia y la vista de las causas ante las Cortes de Apelaciones, es una manifestación del principio contradictorio que rige en el nuevo sistema penal y que constituye un elemento del derecho a defensa y, además, del debido proceso, por cuanto la imparcialidad del tribunal se asegura y garantiza a través del veto a su iniciativa probatoria.

${ }^{25}$ En este sentido, por ejemplo, la sentencia de la E. Corte Suprema, que acoge la apelación de la resolución de la I. Corte de Apelaciones de Concepción que había rechazado un amparo constitucional 
Ahora bien, este principio de contradicción tiene plena virtualidad cuando se le considera como un mandato dirigido al legislador ordinario, para que regule el proceso partiendo de la base de que las partes han de disponer de plenas facultades procesales para tender a conformar la resolución que debe dictar el órgano jurisdiccional, mientras que el derecho de defensa se concibe como un derecho de rango fundamental, atribuido a las partes de todo proceso, que consiste básicamente: 1) En la necesidad de que éstas sean oídas, en el sentido de que puedan alegar y demostrar para conformar la resolución judicial, y 2) En que las partes conozcan y puedan rebatir sobre todos los materiales de hecho y de derecho que puedan influir en la resolución judicial.

En consecuencia, la contradicción del proceso implica que serán las partes quienes fijen la competencia del tribunal a través de las causales que ellas esgrimen en sus recursos, y con sus argumentaciones fijarán la controversia, y construirán con sus argumentaciones la resolución que conforme con el artículo 384 del CPP el tribunal de nulidad deba dictar. Por ello, el que las Cortes omitan resolver todos los asuntos debatidos, implica que el actuar del tribunal "no se ajusta al mérito de lo debatido" (considerando octavo de la sentencia Rol ( $\left.N^{\circ} 493-2011\right)$, lo cual implica que el "impugnante... no estará en condiciones de conocer la suerte de todos los extremos de su recurso" (considerando séptimo de la sentencia Rol № 493-2011), lo que implica hacer ilusoria la garantía del "derecho al recurso" que hemos venido revisando intentando destacar la importancia de no vaciar de contenido derechos y deberes ligados sin los cuales la garantía en comento quedaría a la deriva.

\section{Cierre}

Desde nuestra perspectiva, las sentencias de la E. Corte Suprema que se han analizado en este comentario implican, en lo fundamental, un necesario correctivo a una práctica dañina de parte de algunos tribunales superiores y un resguardo a la garantía de que el condenado cuente verdaderamente con el

contra una sala de la misma Corte, sentencia de fecha 22 de noviembre de 2010, Rol 8772-2010, y que dispone: "Que de lo informado a fojas 11 se desprende que la medida cautelar personal de prisión preventiva decretada en contra de Christopher Nicolás Moreno Aburto, dispuesta por la Corte de Apelaciones de Concepción, tuvo como único fundamento la existencia de diligencias pendientes que impedían la libertad del imputado, en circunstancias que la discusión en relación a la procedencia de la prisión preventiva se circunscribió al presupuesto material contemplado en la letra b) del artículo 140 del Código Procesal Penal, esto es, que existan antecedentes que permitan presumir fundadamente que el imputado ha tenido participación en el delito como autor, cómplice o encubridor, de forma que el tribunal de alzada se pronunció sobre un aspecto no debatido en la audiencia respectiva, vulnerando expresamente lo preceptuado en el artículo 360 del citado cuerpo legal que prohíbe al tribunal que conoce de un recurso extender el efecto de su decisión a cuestiones no planteadas por los intervinientes o más allá de los límites de lo solicitado, transformando, en consecuencia, en ilegal la privación de libertad del amparado". 
derecho al recurso para impugnar una condena que considere adoptada con vicios y errores que le ocasionan un perjuicio en sus intereses, reforzando, además, la efectividad de los derechos al juicio previo y al debido proceso, por la vía de fortalecer las exigencias de la adecuada fundamentación de la sentencia de nulidad, lo que no puede entenderse sino como consecuencia del deber de fundamentación y contradicción ya presentes en el sistema procesal penal.

Tras la entrada en vigencia de la reforma procesal penal el modelo impugnativo se modificó, trasladando el protagonismo desde el recurso de apelación al recurso de nulidad. La cuestión apareja consecuencias y no es gratuita desde el punto de vista de los derechos de los justiciables, más cuando como hemos visto se ha consolidado un criterio restrictivo en el acceso al mecanismo recursivo. Bien se ha explicado que "el carácter ordinario o extraordinario del recurso incide de manera diversa sobre el acceso a la tutela judicial efectiva mediante el recurso ${ }^{\prime 26}$. Cuando el sistema impugnativo permite que conjuntamente con el recurso ordinario, se pueda acceder a otra instancia procesal ad quem mediante el recurso extraordinario, la tutela judicial efectiva es evidentemente más determinante. En cambio, cuando el sistema impone que se pase directamente a la vía extraordinaria, sin existir un acceso previo a la vía ordinaria del recurso, el logro de la tutela judicial efectiva es claramente menos incisiva y penetrante ${ }^{27}$. Es este el escenario para el justiciable tras la reforma procesal penal.

Es justamente la restricción que se genera a propósito de la centralidad del recurso extraordinario de nulidad la que obliga a todos los operadores, en especial a la E. Corte Suprema, cuidar celosamente el respeto del contenido de los derechos fundamentales ligados a un ya debilitado derecho al recurso en nuestro país. La diferencia entre asumir este cuidado y no hacerlo marcará que en lo que liga con el sistema recursivo la reforma procesal penal haya constituido un progreso procesal o bien, una verdadera reformatio in peius para los justiciables.

${ }^{26}$ Lorca Navarrete, A., Tratado de Derecho procesal civil. Parte general: El nuevo proceso civil, Ed. Dykinson, Madrid, 2000, p. 1026.

${ }^{27}$ LorCA, Tratado, cit. nota n. 26, p. 1026. 